\title{
Análise dos Relatórios de Administração das Companhias Abertas Brasileiras: um Estudo do Exercício Social de 2002
}

\author{
César Augusto Tibúrcio Silva \\ Fernanda Fernandes Rodrigues \\ Robson Lopes Abreu
}

\section{Resumo}

O Relatório da Administração (RA) é um relatório narrativo, no qual a empresa tem certa liberdade de apresentar notícias da empresa. Pesquisas empíricas realizadas com o intuito de verificar o grau de utilidade, transparência e confiabilidade destes relatórios demonstraram que eles são utilizados para decisões de investimento; entretanto, verificou-se também que estes relatórios são influenciados pelo viés da administração, na medida em que esta apresenta as informações segundo os seus interesses. O estudo analisa os Relatórios da Administração extraídos da base de dados da CVM do ano de 2002 e verifica se existe relação entre estes e o resultado financeiro das companhias. Os resultados encontrados mostram que o Relatório da Administração possui informação relevante sobre as companhias analisadas. As principais conclusões verificadas no estudo revelam que os relatórios otimistas apresentam maior volume de frases sobre reforma administrativa; já os relatórios pessimistas centram sua atenção na conjuntura econômica. Contatou-se que empresas que apresentam crescimento no ativo possuem relatórios mais extensos. Por outro lado, o aumento no lucro provoca uma redução no relatório. Foi observado ainda que o pessimismo do relatório se refere a uma entidade que possui um ativo e um patrimônio líquido menor que do passado.

Palavras-chave: Relatório da Administração; resultado financeiro; análise de conteúdo; otimismo/ pessimismo.

\begin{abstract}
Management Report (MR) is one of the component of the set of documents that a company discloses to the public. Empirical researches made with the intention to verify the utility grade, transparence and confidence of these reports, demonstrated that they are used on investments decisions; furthermore, it was also observed that reports are influenced by manager's biases as they present information according to their interests. The study analyses management's reports extracted from CVM's 2002 database and checks the existence of relationship between these reports and the financial results of the companies. The results show that management's reports have important information about the analyzed companies. The most important results are that optimist reports present a higher volume of phrases about administrative restructuring; otherwise, pessimist reports focus on the economic situation. Companies with an increasing assets present longer reports. On the other hand, increasing profits result in reduced reports. Reports with a pessimist tone match with entities that have liabilities bigger than the assets and the equity.
\end{abstract}

Key words: Management Reports; financial results; content analysis; optimism/pessimism. 


\section{INTRODUÇÃO}

As empresas podem ser vistas como um conjunto de contratos entre as partes interessadas, os quais devem convergir para o cumprimento das expectativas dos agentes (Sunder, 2002). Entretanto, conflitos de interesses entre estes podem levar a perdas substanciais para as organizações. Este problema é abordado especulativamente pela teoria da agência, a qual considera, entre outras proposições, que o comportamento dos gestores e, conseqüentemente, a divulgação de seus atos e decisões, pode ser conflitante com o interesse dos stakeholders, uma vez que esta divulgação privilegiará seus próprios interesses.

Os custos de resolução destes conflitos de interesse são denominados custos de agência (agency costs), podendo ser definidos como a soma de (1) custos de monitoramento pelos acionistas e (2) custos de implantação de mecanismos de controle (Stadler \& Pérez-Castrillo, 2001, por exemplo). Os problemas de agência nunca podem ser resolvidos com perfeição e, conseqüentemente, podem levar os acionistas a sofrerem perdas residuais (Ross, Westerfiel, \& Jaffe, 2002, p. 34). Weston e Brigham (2000, p. 19) afirmam que existem vários mecanismos que podem ser utilizados com o objetivo de motivar os gerentes a agir no melhor interesse dos acionistas, sendo que alguns destes são a ameaça de demissão, a ameaça de tomada de controle ou mesmo a compensação administrativa. Segundo Lima (1999, p. 150), a teoria da agência, em ambiente de assimetria de informações, apresenta-se de caráter relevante, já que o agente e o principal possuem diferentes níveis de informação. Assim, os demonstrativos e relatórios contábeis entram em cena como instrumentos que possibilitam a redução deste conflito. Esta concepção é sustentada pelo conceito de que os demonstrativos materializam a teoria do conhecimento comum. Neste contexto, o conhecimento comum representa o compartilhamento de informações, de forma que a informação em poder de um agente é conhecida por um segundo, o qual sabe que o primeiro a possui, e ao mesmo tempo sabe que outros sabem que ele e o primeiro a possuem, e assim sucessivamente (Sunder, 2002).

Yuthas, Rogers e Dillard (2002) consideram que o texto contido nos relatórios da administração é amplamente lido por uma variedade de stakeholders e analistas. Distorções significativas feitas pelos gestores podem trazer malefícios a longo prazo, se for descoberto que estas distorções informacionais teriam afetado a percepção dos demonstrativos financeiros.

Neste sentido, esta pesquisa tem por objetivo verificar se os Relatórios da 
Administração representam fonte de informação sobre a empresa. Assim a pesquisa se apresenta dividida em seis seções, além desta introdução. A seguir trata-se da importância do relatório da administração; posteriormente apresentamse pesquisas sobre esses relatórios e a sua utilidade e confiabilidade. Nas seções seguintes, apresenta-se o problema deste estudo, bem como a metodologia e a descrição dos dados utilizados. A seção final apresenta as proposições da pesquisa. Finalmente as conclusões deste estudo são mostradas.

\section{O Relatório da Administração e sua Importância}

Segundo alguns teóricos da contabilidade (Hendriksen \& Van Breda, 1999, p. 99; Iudícibus, 2000, p. 20), o objetivo desta é fornecer informações úteis à tomada de decisão. Niyama (1989, p. 19) acrescenta que esses usuários necessitam de informações claras e compreensíveis, a fim de poderem avaliar a posição econômico-financeira da empresa e extrair conclusões que contribuam para formar seu juízo de forma confiável.

Entretanto decidir sobre o que é útil ou não para o usuário tomar decisões econômicas é tarefa difícil. Isto ocorre em virtude da grande quantidade de diferentes usuários, que utilizam as informações geradas de diferentes maneiras em suas tomadas de decisões. Neste sentido as demonstrações contábeis constituem-se na maior parte das informações da empresa às quais o usuário externo tem acesso. E, por este motivo, devem conter estas informações os dados financeiros relevantes e importantes. A situação financeira ainda pode ser apresentada através de forma narrativa, pela própria administração da empresa. No Brasil, esta narrativa é denominada Relatório da Administração.

Assim, o conjunto de informações que os administradores fornecem aos acionistas, credores e comunidade em geral representa os Documentos da Administração, conforme previsto no art. 133 da Lei 6.404 (Brasil, 1976); tal conjunto é composto pelo Relatório da Administração (RA), pelas Demonstrações Financeiras (Balanço Patrimonial, Demonstração do Resultado do Exercício, Demonstração das Origens e Aplicação dos Recursos, Demonstração do Lucro ou Prejuízo Acumulado e Demonstração das Mutações do Patrimônio Líquido) com Notas Explicativas e pelo Parecer dos Auditores Independentes. O Relatório da Administração não faz parte das demonstrações financeiras propriamente ditas, mas esta lei exige a apresentação desse relatório, que deve evidenciar os negócios sociais e principais fatos administrativos ocorridos no exercício, os investimentos em outras empresas, a política de distribuição de dividendos e de reinvestimento de lucros, entre outros. 
Este Relatório, por ser menos técnico e mais descritivo que os outros documentos, tem forte poder de comunicação, podendo prestar conta dos atos praticados e apresentar expectativas sobre desempenhos futuros. Faz-se relevante a apresentação deste, na medida em que a Administração "[...] sabe mais sobre a empresa e suas atividades do que investidores, credores e outras pessoas fora da empresa e, muitas vezes, pode aumentar a utilidade de informações financeiras, identificando certas transações, outros eventos e circunstâncias que afetam a empresa, explicando seu impacto financeiro" (Fasb, como citado em Hendriksen \& Van Breda, 1999, p. 529).

Embora seja de utilidade e relevância para os investidores, estes relatórios são considerados por boa parte da literatura como enviesados. Exemplo disso pode ser observado em Iudícibus (2000, p. 20), que afirma que os relatórios "normalmente são enviesados pelo lado do otimismo inconseqüente, sendo comuns frases com esta: 'Confiamos que continuaremos a apresentar um desenvolvimento favorável de nossas operações no futuro' e outras do gênero". Da mesma maneira, a revista Forbes (Novembro, 1996, como citado em Yuthas et al., 2002) afirma que o "o relatório anual é uma ferramenta de marketing para atrair novos investidores" (tradução nossa). Por ser este relatório de grande impacto nos investidores externos (Rogers \& Grant, 1997, como citado em Yuthas et al., 2002; Springer, 1992) é que se observa a relevância de pesquisas científicas que analisem se este relatório apresenta realmente este viés da administração, sendo apenas "ferramentas de marketing", ou se são realmente confiáveis para tomadas de decisões.

\section{Referencial Teórico}

Segundo Springer (1992), a parte dos relatórios anuais que mais freqüentemente ajuda os acionistas a analisar os resultados financeiros do ano anterior e as previsões futuras da companhia é o Relatório da Administração. Pesquisa realizada por Rogers e Grant (1997, como citado em Yuthas et al., 2002) analisou as informações contidas nos relatórios financeiros de mais de 190 diferentes companhias e conclui que o Relatório da Administração é a seção mais citada por analistas de mercado.

Em pesquisa realizada por Yuthas et al. (2002), os autores avaliaram as características dos Relatórios da Administração, utilizando os princípios de ação comunicativa de Jürgen Habermas - compreensibilidade, confiabilidade, sinceridade e legitimidade. Os resultados alcançados sugerem que, comparadas às empresas neutras, as empresas que esperam algum tipo de surpresa tendem a apresentar relatórios mais comunicativos. Os autores perceberam ainda que 
empresas com más notícias tendem a apresentar menos referências a si mesmas nos relatórios, na tentativa de ligar seu desempenho insatisfatório a fatores externos. Por fim, empresas que apresentam boas notícias parecem não tentar distorcer as percepções sobre seu desempenho.

Sobre este relatório, a Securities and Exchange Commission - SEC (1987, como citado em Bryan, 1997) há tempo reconheceu a necessidade da explicação narrativa dos relatórios financeiros, em virtude de a apresentação numérica e as sínteses feitas nas notas de rodapé somente, às vezes, serem insuficientes para um investidor julgar sobre dividendos e sobre a probabilidade do desempenho passado ser indicativo de desempenho futuro. A Comissão de Valores Mobiliários (CVM) também corrobora a SEC, sobre a importância do Relatório ao afirmar que

A divulgação de informações úteis, fidedignas e detalhadas, que possibilitem o conhecimento da companhia e de seus objetivos e políticas, é um direito essencial do acionista. O relatório da administração não pode ser excluído dessa premissa; assim, tanto a falta de informações quanto a inclusão de estudos e fatos genéricos que não dizem respeito à situação particular da companhia constituem desatendimento ao interesse e ao direito do investidor. (CVM, 1987).

Por ser este relatório de grande importância aos acionistas e por ser uma evidenciação narrativa não-auditada, tornam-se necessários estudos que confirmem a transparência das informações prestadas pela administração. A literatura americana percebeu tal necessidade e apresenta pesquisas realizadas com esta prerrogativa. Segundo Darrough e Stoughton (1990, como citado em Boo \& Simnett, 2002), esta relação entre administração e acionistas se aproxima da teoria dos jogos, na medida em que as companhias se empenham em evidenciar seletivamente, na finalidade de atender aos seus próprios objetivos. Neste sentido, os autores afirmam que, em situações financeiras difíceis, os administradores tendem a exagerar em frases sobre a perspectiva futura da companhia, o que se pode entender que, embora a empresa esteja com problemas financeiros, ela tem perspectivas de melhoria.

Boo e Simnett (2002, p. 283) realizaram pesquisa com o objetivo de verificar se companhias com dificuldades financeiras que evidenciam relatórios otimistas são mais prováveis de falir no próximo ano do que as outras empresas com dificuldades financeiras. Para o estudo, os autores classificaram as frases dos relatórios em otimistas, pessimistas, mistas ou omissas, com o objetivo de verificar se os relatórios das empresas que apresentavam maior quantidade de frases otimistas tinham maior tendência à falência. Os autores constatam que as empresas com problemas financeiros e que omitem informações em seus 
relatórios têm maior probabilidade de falir do que as demais, o que corrobora a teoria da seletividade de disclosure em contextos de dificuldades financeiras, apresentada por Darrough e Stoughton.

D'Aveni e MacMillan (1990, como citado em Yuthas et al., 2002) compararam cartas para acionistas de administradores seniores de firmas em crise financeira. Os autores observaram que, enquanto as firmas que sobreviveram focam em fatores externos e internos, as que faliram tenderam a focar somente no ambiente externo.

Pava e Epstein (1993) constataram que, em uma amostra de 25 empresas, a administração tende a antecipar muito mais boas notícias do que más notícias, o que demonstra um viés da administração. Como exemplo de boas notícias, pode-se citar um resultado financeiro maior que o esperado, ou de más notícias a perda de uma ação judicial, mesmo quando de possibilidade provável. Yuthas et al. (2002) cita os trabalhos de Salancik e Meindl (1984) e Staw et al. (1983), os quais investigaram a maneira como os administradores descrevem os resultados de seus esforços nos relatórios anuais e constataram que os administradores tipicamente levam créditos por boas notícias e culpam o ambiente por más notícias.

Lambert (2001) considera que um dos principais paradigmas teóricos dos últimos vinte anos para a contabilidade tem sido a teoria da agência, principalmente por permitir aos pesquisadores incorporar os conflitos de interesse em seus estudos. O autor exemplifica com o argumento de que a razão para se insistir na contratação de auditoria independente é que não se confia que os gestores emitirão relatórios confiáveis.

Watson (2002) realizou pesquisa para verificar se a teoria da agência ou a teoria da sinalização explicariam o disclosure voluntário de indicadores nas demonstrações anuais. Segundo o autor, o disclosure voluntário reduz os custos de agência, na medida em que os agentes não necessitam buscar novas informações em outras partes. Já a teoria da sinalização, seria uma reação às assimetrias informacionais existentes no mercado. As assimetrias ocorrem quando as companhias possuem informações que os investidores não possuem, sendo que estas podem ser reduzidas, se a parte com maior informação sinalizar à outra e que, quando o desempenho da companhia é bom, elas desejam apontar suas qualidades aos investidores. Assim, a pesquisa constatou, entre outras evidências, que o desempenho da companhia representa um determinante do disclosure de indicadores, sendo que, se a rentabilidade marginal da companhia é maior que a média, então os administradores serão mais propensos a divulgar mais informações sobre a situação financeira aos acionistas e investidores, o que é coerente com a 
teoria da sinalização. Para o autor, se a administração tem confiança em suas habilidades e em suas estratégias, ela não terá receio de divulgar ao mercado como está atuando no presente e os seus planos para o futuro.

Ainda sobre disclosure voluntário, Eng e Mak (2003) procuraram verificar a existência de relação entre este e os aspectos de governança corporativa. Os estudos foram realizados a partir de uma amostra de 158 empresas listadas na Bolsa de Valores de Singapura, e os resultados verificaram que a estrutura do capital afeta o disclosure, na medida em que uma menor participação dos administradores e uma maior participação do governo influenciam maior disclosure voluntário. Os autores concluíram ainda que firmas maiores e com menor endividamento apresentaram relatórios mais volumosos.

Em pesquisa realizada por Bryan (1997), o autor quis avaliar a eficácia do Relatório da Administração. Para isto, ele classificou os relatórios em favorável e desfavorável, de acordo com a opinião explícita do administrador, e em neutro ou omisso, conforme o julgamento do pesquisador. Os resultados apresentados foram no sentido de que nos relatórios, particularmente em relação às discussões de operações futuras e investimentos de capital planejado, são associados com medidas de desempenho futuras e decisões de investimentos. Desta forma, as demonstrações financeiras em conjunto com o Relatório da Administração podem auxiliar os investidores em avaliar as perspectivas futuras da empresa.

No Brasil, os livros de análise de balanço centram sua atenção nas informações quantitativas contidas nas demonstrações contábeis, não discutindo de maneira adequada o Relatório de Administração (RA), limitando-se a descrevê-lo brevemente (vide, por exemplo, Assaf Neto, 2002). Em especial, um esforço analítico tem sido feito na utilização dos indicadores de análise ou na evolução dos preços das ações. Isso ocorre por duas razões principais. Em primeiro lugar, as bases de dados enfatizam essas informações. Um exemplo disso é a base da Economática, que apresenta com ênfase as informações quantitativas, mas dispõe, de forma limitada para seus usuários, as informações qualitativas das notas explicativas, do parecer do auditor ou do relatório da administração. Outro exemplo são as bases de dados das revistas econômicas, como a Exame, Valor ou FGV, que centram seus relatórios em alguns poucos índices. O segundo aspecto, e tão relevante quanto o primeiro, diz respeito à facilidade de fazer pesquisa empírica com os valores monetários e indicadores financeiros. Isto ocorre, porque, nas pesquisas com variáveis qualitativas, o pesquisador, antes da realização dos testes, precisa criar parâmetros que tornem esta variável quantitativa, para daí então, poder efetuar os testes estatísticos.

ACVM, já atentou para os problemas decorrentes do Relatório da Administração 
e, desde o advento da Lei $\mathrm{N}^{\circ}$ 6.404/76, ela vem examinando o conteúdo destes relatórios apresentados anualmente pelas companhias abertas. Esta comissão aponta que é expressivo o número de empresas que apresentam o relatório de modo sucinto, utilizando para tanto as mais variadas justificativas, entre as quais "ressaltamos a de que os informes necessários para análise dos aspectos em exame já estão contidos nas notas explicativas" (CVM, 1987), também não sendo válida a simples apresentação de percentuais, que podem ser obtidos por qualquer leitor das demonstrações contábeis, visto que a informação relevante diz respeito ao comentário ou apreciação dos fatores endógenos e exógenos que influenciaram as variações ocorridas.

De acordo com a CVM, tal procedimento, além de infringir a lei, não é compatível com a postura que se espera de uma companhia aberta, acarretando a perda de uma valiosa oportunidade de a companhia ser mais bem conhecida e avaliada pelo público investidor, por seus clientes, fornecedores e credores. Por isto, somente no exercício de 2003, a CVM determinou a republicação de 66 relatórios por não atenderem ao mínimo requerido pelas disposições acima. Na maior parte desses relatórios, segundo a comissão, os administradores se limitaram tão-somente a apresentar as demonstrações financeiras, agradecendo a colaboração de funcionários, credores etc. e se colocando à disposição dos acionistas para maiores esclarecimentos.

\section{Problema}

Assim, a partir da exposição anterior, o problema que efetivamente se apresenta é: OS RELATÓRIOS DE ADMINISTRAÇÃO REPRESENTAM FONTE DE INFORMAÇÃO DE UMA ENTIDADE?

Conforme Viegas (1999, p. 67) "ciência é o conhecimento das coisas por intermédio das causas" e desta forma, separando-se a causa do efeito, é que se percebe a relação entre dois fenômenos. Os estudos de informação contábil de uma entidade concentram-se nas informações quantitativas. Existem, entretanto, na literatura científica, estudos que nos mostram a possibilidade de se utilizar dados qualitativos (Boo \& Simnett, 2002; Bryan, 1997; Sullivan \& Benke, 1997; Young \& Guenther, 2002; dentre outros). Para isto é necessário que se adotem critérios (atributos) de comparabilidade capazes de classificar os dados desta variável de forma ordinal, técnica denominada análise de conteúdo.

A análise de conteúdo, segundo Freitas e Janissek (2000, p. 37) "é uma técnica de pesquisa para tornar replicáveis e validar inferências de dados de um contexto 
que envolve procedimentos especializados para processamento de dados de forma científica”. Estes autores afirmam que esta técnica pode ser usada para analisar em profundidade cada expressão específica, o que torna possível analisar as entrelinhas das opiniões das pessoas, não se restringindo às palavras expressas diretamente, mas também àquelas subentendidas no discurso.

\section{Metodologia e Descrição dos Dados}

Para cumprir os objetivos desse trabalho, optou-se por utilizar a regressão linear múltipla. Conforme Hair, Anderson, Tatham e Black (1998), a regressão pode ser utilizada quando se deseja verificar a existência de relação entre uma variável dependente e uma ou mais variáveis independentes.

Os dados foram obtidos na Comissão de Valores Mobiliários, nas demonstrações contábeis que as empresas entregam a esse órgão. Como se pretende verificar a existência de relação entre as informações contábeis contidas nos RA e o desempenho passado e futuro da entidade, utilizaram-se como referências as demonstrações do exercício findo em 31 de dezembro de 2002. Para fins desse trabalho foram eliminadas as entidades do setor financeiro em decorrência das peculiaridades desse setor. Após essa depuração, levantaram-se os RA de 448 entidades.

As informações obtidas podem ser agrupadas da seguinte forma:

a) Informação Quantitativa dos RA - Compreende o número de palavras, frases, letras e gráficos e tabelas. A contagem foi feita utilizando o processador de texto para os três primeiros itens. A partir dessa informação primeira, calculouse o número médio de palavras em cada frase e o número de letras por frase.

b) Informação qualitativa dos RA - Cada frase foi classificada em otimista, pessimista ou neutra. A Tabela 1 apresenta alguns exemplos dessa classificação. Ademais, as frases foram classificadas em doze grupos segundo o assunto, conforme apresentado na Tabela 2, que apresenta também exemplos de como foram feitas as classificações. O processo de classificação foi feito pelos pesquisadores, sendo que uma mesma frase recebeu duas classificações, quanto ao otimismo e quanto ao assunto.

c) Informação quantitativa de desempenho - foram retirados alguns indicadores de desempenho das demonstrações contábeis, conforme apresentado na Tabela 3. 
Tabela 1: Exemplos do Grau de Otimismo, Pessimismo e Neutralidade do Relatório

\begin{tabular}{ll}
\hline Classificação & \multicolumn{1}{c}{ Exemplo } \\
\hline Neutra & $\begin{array}{l}\text { Em 27 de setembro de 2002, os acionistas deliberaram incluir no objeto social da companhia a } \\
\text { prestação de serviços de consultoria, administração, comunicação e/ou atendimento. }\end{array}$ \\
\hline Otimista & $\begin{array}{l}\text { Não obstante as dificuldades verificadas, a [empresa] permaneceu líder de mercado, com 64\% do } \\
\text { market share. }\end{array}$ \\
\hline Pessimista & $\begin{array}{l}\text { O resultado da [empresa] foi altamente prejudicado no ano de 2002, em função da variação } \\
\text { cambial que foi de 52\%. }\end{array}$ \\
\hline
\end{tabular}

Fonte: elaboração própria.

Tabela 2: Exemplos do Assunto Tratado

\begin{tabular}{|c|c|}
\hline Assunto & Exemplo \\
\hline $\begin{array}{l}\text { Apresentação/ } \\
\text { Conclusão }\end{array}$ & $\begin{array}{l}\text { Apresentamos as Demonstrações Financeiras, relativas ao exercício findo em } 31 \text { de } \\
\text { dezembro de } 2002 \text {. } \\
\text { Finalmente, agradecemos aos nossos gerentes, colaboradores, clientes, fornecedores e } \\
\text { parceiros que contribuíram para o desempenho satisfatório [...] }\end{array}$ \\
\hline $\begin{array}{l}\text { Descrição do } \\
\text { Negócio }\end{array}$ & No final do exercício, contávamos com 185 lojas, com $78.571 \mathrm{~m}^{2}$ de área de venda, [...] \\
\hline Cenário Econômico & $\begin{array}{l}\text { O ano de } 2002 \text { foi bastante difícil para o mercado mundial com incertezas políticas e } \\
\text { econômicas, prejudicando o País por ter dependência de influxos de investimentos } \\
\text { estrangeiros. }\end{array}$ \\
\hline $\begin{array}{l}\text { Reformas da } \\
\text { Administração }\end{array}$ & $\begin{array}{l}\text { Foram implementadas novas rotinas e melhorias no Sistema de Informações ao Cliente } \\
\text { para atendimento às determinações [...] e aprimoramento da prestação dos serviços aos } \\
\text { clientes. }\end{array}$ \\
\hline Desempenho & $\begin{array}{l}\text { A receita operacional líquida do exercício foi } \mathrm{R} \$ 323,0 \text { milhões, } 5,4 \% \text { acima do exercício } \\
\text { anterior. }\end{array}$ \\
\hline Auditoria & $\begin{array}{l}\text { Durante o exercício de } 2002 \text {, o valor correspondente aos serviços não relacionados à } \\
\text { auditoria externa foi inferior a } 5 \% \text { dos referidos honorários. }\end{array}$ \\
\hline Investimento & $\begin{array}{l}\text { Os investimentos em terrenos, prédios, instalações e equipamentos efetuados pelas três } \\
\text { empresas no referido site industrial durante os anos de } 2001 \text { e } 2002 \text { atingiram R\$ } 25,5 \\
\text { milhões. }\end{array}$ \\
\hline Dividendos & $\begin{array}{l}\text { Tais proposições importarão em distribuir aos acionistas a quantia líquida do imposto de } \\
\text { renda de } \mathrm{R} \$ 12.782 .587,04 \text {, equivalente a } 27,9 \% \text { do lucro líquido ajustado de } \mathrm{R} \$ \\
45.727 .481,48 \text {. }\end{array}$ \\
\hline
\end{tabular}

Capital Social/ Em 31 de dezembro de 2002 e 2001, o capital social, subscrito e integralizado, está Estrutura representado por 8.174.011.326 (7.701.777.315 em 2001) ações nominativas, sendo 3.662.193.562 (3.450.619.042 em 2001) ordinárias, 800 preferenciais classe A, 4.133.582.190 (3.894.774.313 em 2001) preferenciais classe B, 83.580.677 (78.752.002 em 2001) preferenciais classe C e 294.654 .097 (277.631.158 em 2001) preferenciais classe D, todas sem valor nominal.

\begin{tabular}{ll}
\hline $\begin{array}{l}\text { Endividamento/ } \\
\text { Financiamento }\end{array}$ & $\begin{array}{l}\text { Em 2002 a [empresa] reduziu seu endividamento bruto consolidado em US\$ 60 milhões, } \\
\text { passando de US\$ 445 milhões em 31 de dezembro de 2001 para US\$ 385 milhões em 31 } \\
\text { de dezembro de 2002. }\end{array}$ \\
\hline Perspectivas & $\begin{array}{l}\text { Espera-se um crescimento do PIB em 2003, ainda que as previsões sejam modestas, com } \\
\text { uma evolução favorável nas contas externas e no balanço de pagamentos. }\end{array}$ \\
\hline Outras Informações & $\begin{array}{l}\text { As ações da companhia são negociadas em todas as bolsas de valores do Brasil, desde } \\
\text { março de 1982. }\end{array}$ \\
\hline
\end{tabular}

Fonte: elaboração própria. 
Tabela 3: Grupos e Variáveis Estudadas

\begin{tabular}{|c|c|c|}
\hline & Objetivo & Abreviatura \\
\hline \multirow{6}{*}{ Informação Quantitativa dos RA } & número de palavras & (PALAVRA) \\
\hline & número de frases & (FRASE) \\
\hline & número de letras & (LETRA) \\
\hline & número de gráficos e tabelas & (GRAFTAB) \\
\hline & número médio de palavras em cada frase & (PLAFRAS) \\
\hline & número de letras por frase & (LETFRAS) \\
\hline \multirow{15}{*}{ Informação Qualitativa dos RA } & otimista & (OTIMISMO) \\
\hline & pessimista & $($ PESSIMISMO $)$ \\
\hline & neutra & (NEUTRA) \\
\hline & Apresentação/Conclusão & (APRESENTAÇÃO) \\
\hline & Descrição do Negócio & (DESCRIÇÃO) \\
\hline & Conjuntura Econômica & (CONJUNTURA) \\
\hline & Reforma da Administração & (REFORMA) \\
\hline & Desempenho & (DESEMPENHO) \\
\hline & Auditoria & (AUDITORIA) \\
\hline & Investimento & (INVESTIMENTO) \\
\hline & Dividendo & (DIVIDENDO) \\
\hline & Capital Social/Estrutura & (ESTRUTURA DE CAPITAL) \\
\hline & Endividamento/Financeiamento & (ENDIVIDAMENTO) \\
\hline & Perspectiva & (PERSPECTIVA) \\
\hline & Outras Informações & (OUTRAS) \\
\hline \multirow{6}{*}{ Informação Quantitativa de Desempenho } & ativo & $(A T I V O)$ \\
\hline & lucro líquido & $(L L)$ \\
\hline & liquidez & (LIQUI) \\
\hline & patrimônio líquido & $(P L)$ \\
\hline & retorno do ativo & $(R S A)$ \\
\hline & endividamento de curto prazo & $($ ENDIV) \\
\hline
\end{tabular}

Fonte: elaboração própria.

A Tabela 4 apresenta a estatística descritiva das informações quantitativas dos RA. O apêndice A apresenta a descrição das variáveis estudadas constantes da Tabela 4. Conforme pode ser observado, o tamanho do RA pode variar de relatórios com 28 palavras (da empresa ALL América Latina Logística) até 18.320 (da Brasil Telecom). Ao todo, foram analisados relatórios com um total de 747 mil palavras, três vezes mais o número de verbetes de um dicionário da língua portuguesa. Em média os RA apresentaram um número de 1.668 palavras, com 44 frases. Cada uma das frases apresentou uma média de 13,4 palavras. O número de tabelas e gráficos foi de 1.048, com uma média de 2,3 por documento e valor máximo de 30 (Brasil Telecom). 
Tabela 4: Estatística Descritiva dos RA - 2002

\begin{tabular}{llllllll}
\hline & $\mathrm{N}$ & Mínimo & Máximo & Média & Desvio-Padrão & Assimetria & Curtose \\
\hline PALAVRA & 448 & 28 & 18.320 & $1.668,4844$ & $2.299,6126$ & 3,514 & 18,350 \\
FRASE & 448 & 1 & 525 & 46,9420 & 63,9810 & 3,772 & 21,252 \\
LETRAS & 448 & 181 & 98.026 & $9.156,3594$ & $12.255,7247$ & 3,462 & 18,191 \\
PALFRAS & 448 & 18 & 184 & 35,2701 & 12,5054 & 5,045 & 47,406 \\
LETPAL & 448 & 0 & 28 & 4,0335 & 2,8695 &, 640 & 9,315 \\
LETFRAS & 448 & 11 & 1.336 & 219,2656 & 158,7651 & 2,763 & 10,777 \\
GRAFTAB & 446 & 0 & 30 & 2,3498 & 4,6329 & 2,912 & 10,425 \\
\hline
\end{tabular}

Fonte: elaboração própria.

Uma informação importante pode ser obtida pela matriz de correlação de Pearson das variáveis. Como já era esperado, RA com um grande volume de palavras também deve possuir mais frases e letras. Além disso, esses relatórios mais extensos, expressos pelo número de palavras, possuem frases mais complexas, onde o número de palavras por frase é maior. Os relatórios mais extensos também são aqueles que mais se utilizam de gráficos e tabelas.

Tabela 5: Matriz de Correlação das Informações Quantitativas dos RA - 2002

\begin{tabular}{|c|c|c|c|c|c|c|c|}
\hline & PALAVRA & FRASE & LETRA & PALFRAS & LETPAL & LETFRAS & GRAFTAB \\
\hline PALAVRA & & ,944** & ,987** & $281 * *$ &,- 038 &, $390 * *$ & $675 * *$ \\
\hline FRASE & & &, $948 * *$ & 018 &,- 053 & $342 * *$ & $669 * *$ \\
\hline LETRA & & & & $256 * *$ &,- 001 & $416^{* *}$ & $687 * *$ \\
\hline PALFRAS & & & & & 020 &, $307 * *$ &, $111^{* *}$ \\
\hline LETPAL & & & & & &,- 068 &,$- 098 *$ \\
\hline LETFRAS & & & & & & & $436 * *$ \\
\hline GRAFTAB & & & & & & & \\
\hline
\end{tabular}

** Correlação é significante a 0,01 (bicaudal)

* Correlação é significante a 0,05 (bicaudal).

Fonte: elaboração própria.

\section{Proposições da Pesquisa}

A resposta à questão pesquisa está dividida em dez proposições. O Apêndice $\mathrm{B}$ apresenta os resultados estatísticos obtidos, que estão referenciados no texto a seguir.

\section{Proposição 1 = Empresas de maior porte possuem relatórios mais extensos.}

Para verificar essa proposição foi realizada a regressão entre o logaritmo natural do ativo de cada entidade e o número de palavras. A regressão apresentou relação 
proporcional entre o tamanho da entidade (logaritmo de ATIVO) e o número de palavras. Outra regressão foi calculada, alterando a variável dependente para FRASE e LETRA e o resultado foi aproximadamente o mesmo.

Proposição $2=0$ desempenho passado das empresas interfere no tamanho dos relatórios.

Para testar foi utilizada a regressão linear múltipla, método backward, utilizando o seguinte modelo:

$$
\begin{aligned}
& \text { PALAVRA }=\beta 0+\beta 1 D A T I V O_{-} 02+\beta 2 D L L_{-} 02+\beta 3 D L I Q U I_{-} 02+\beta 4 D P L_{-} 02+ \\
& \beta 5 R S A_{-} 01+\beta 6 R S A_{-} 02+\beta 7 D R S A_{-} 02+\beta 8 D E N D I V_{-} 02+\epsilon i, t
\end{aligned}
$$

As variáveis do modelo estão descritas no apêndice A1. O resultado mostrou que empresas que apresentam crescimento no ativo (DATIVO02) possuem relatórios mais extensos. Por outro lado, o aumento no lucro (DLL02) provoca uma redução no relatório. O mesmo conjunto de variáveis dependentes revela um resultado próximo ao obtido anteriormente, quando se utiliza FRASE e LETRA.

\section{Proposição 3 = O RA antecipa o desempenho futuro da entidade.}

O modelo utilizado é, com as devidas adaptações, aproximadamente o mesmo da proposição 2:

PALAVRA $=\beta_{0}+\beta_{1 \text { DATIVO }_{-} 03+\beta_{2} \text { DLL_ } 03+\beta_{3} \text { DLIQUI }} 03+\beta_{4 D P L_{-} 03}+$ $\beta 5 R S A_{-} 02+\beta 6 R S A_{-} 03+\beta 7 D R S A_{-} 03+\beta 8 D E N D I V_{-} 03+\epsilon i, t$

O resultado encontrado mostra que a extensão do relatório (palavra, frase ou letra) está relacionada com a variação do lucro líquido futuro em relação ao lucro atual. Frase e letra apresentam resultados semelhantes.

Proposição 4 = 0 grau de otimismo do RA reflete o desempenho da entidade.

Foi utilizado o seguinte modelo:

$$
\begin{aligned}
& \text { OTIMISMO }=\beta 0+\beta 1 D L L_{-} 02+\beta 2 D P L_{-} 02+\beta 3 R S A_{-} 02+\beta 4 \text { DLIQUI } 02+ \\
& \beta 5 \text { DATIVO } 02+\beta 6 E N D I V_{-} 02+\beta 7 \text { LIQUI } 02+\beta 8 L L_{-} 02+\beta 9 R S A_{-} 01+ \\
& \beta 10 D R S A_{-} 02+\beta 11 \text { DENDIV }{ }_{-} 02+\epsilon i, t
\end{aligned}
$$


O resultado mostra que o grau de otimismo do relatório decorre do desempenho atual da entidade expresso pelo aumento no ativo e do patrimônio líquido, do volume do lucro, do retorno sobre o ativo e, de forma não esperada, na redução da liquidez.

Proposição 5 = 0 grau de otimismo do RA antecipa o desempenho da entidade.

O modelo corresponde ao da proposição anterior, com as devidas alterações:

OTIMISMO $=\beta 0+\beta_{1 D L L_{-} 03}+\beta_{2 D P L_{-} 03}+\beta 3$ RSA $_{-} 03+\beta$ PDLIQUI_03 + $\beta 10 D R S A_{-} 03+\beta 11 D E N D I V_{-} 03+\in i, t$

O resultado obtido mostra que os RA otimistas são traduzidos somente em aumentos futuros do patrimônio líquido e no retorno do ativo do exercício seguinte.

Proposição $6=0$ grau de pessimismo reflete o desempenho presente da entidade.

Essa proposição é inversa da de número 4. A expressão do modelo seria:

PESSIMISMO $=\beta_{0}+\beta_{1 D L L_{-} 02}+\beta_{2 D P L_{-} 02}+\beta_{3 R S A_{-} 02}+\beta$ PDLIQUI_02 +

$\beta 5$ ATIVO_02 $+\beta 6$ ENDIV ${ }_{-} 02+\beta 7$ LIQUI_0 $02+\beta 8 L L_{-} 02+\beta 9 R S A_{-} 01+\beta 10 D R S A_{-} 02+$

$\beta_{11 D E N D I V+02+\in i, t}$

É interessante notar que o pessimismo do relatório diz respeito a uma entidade que possui ativo e patrimônio líquido menor que do passado.

Proposição $7=0$ grau de pessimismo reflete o desempenho futuro da entidade.

A equação é semelhante àquela aplicada na proposição anterior, com as devidas adaptações. O modelo resultante encontrado mostra uma relação inversa da variação do ativo e do patrimônio líquido da empresa.

\section{Proposição 8 = 0 grau de otimismo/pessimismo possui relação com o assunto discutido no RA.}

Para verificar esse ponto foi calculada a matriz de correlação entre o percentual de frases otimistas, pessimistas e neutras com o percentual de assuntos das frases. Os relatórios otimistas são aqueles que também descrevem a reforma 
administrativa; já os relatórios pessimistas centram sua atenção na conjuntura econômica, conforme pode ser visualizado na Tabela 6 .

Tabela 6: Relação entre Otimismo e Assunto tratado no RA

\begin{tabular}{lrrr}
\hline Assunto & Otimista & Pessimismo & Neutra \\
\hline Apresentação &,$- 394^{* *}$ &,$- 145^{* *}$ &, $446^{* *}$ \\
Descrição do Negócio &,$- 286^{* *}$ &,$- 255^{* *}$ &, $402^{* *}$ \\
Conjuntura &, 080 &, $572^{* *}$ &,$- 375^{* *}$ \\
Reforma &, $555^{* *}$ &,- 087 &,$- 476^{* *}$ \\
Desempenho &, $393^{* *}$ &, $222^{* *}$ &,$- 486^{* *}$ \\
Auditoria &,$- 496^{* *}$ &,- 018 &, $475^{* *}$ \\
Investimento &, $131^{* *}$ &,- 037 &,$- 104^{*}$ \\
Dividendo &,- 011 &,- 010 &, 017 \\
Estrutura de Capital &,- 091 &,$- 111^{*}$ &, $144^{* *}$ \\
Endividamento &, $110^{*}$ &, 006 &,$- 105^{*}$ \\
Perspectiva &, $191^{* *}$ &, $208^{* *}$ &,$- 288^{* *}$ \\
Outras &,$- 191^{* *}$ &,$- 160^{* *}$ &, $263 * *$ \\
\hline
\end{tabular}

** Correlação é significativa a 0,01 (bicaudal)

* Correlação é significativa a 0,05 (bicaudal)

Fonte: elaboração própria.

Proposição 9 - O assunto discutido no RA está relacionado com o desempenho presente da entidade.

Para confirmar essa proposição foram calculadas regressões com as variáveis DLL02, ATIVO02, DPL02, RSA02, DLIQUIO2, LNATIVO02, DATIVO02, utilizando o método backward. Não foi possível estabelecer nenhuma relação para as frases vinculadas à descrição do negócio e à conjuntura.

\section{Apresentação}

A variação negativa do ativo e a redução do lucro líquido causam menor volume de frases de apresentação, enquanto variações positivas do lucro líquido são positivamente relacionadas a um aumento nas frases.

\section{Reforma}

Variações no ativo e no patrimônio líquido explicam um maior volume de frases sobre reformas da administração. Relação inversa ocorre frente a reduções no retorno sobre o ativo.

\section{Desempenho}

As empresas tendem a apresentar maior volume de frases sobre seu 
desempenho, quando as variações no lucro líquido e retorno sobre o ativo são positivas.

\section{Auditoria}

Variações negativas sobre o ativo e lucro líquido explicam um menor volume de frases sobre auditoria.

\section{Investimento}

Variações negativas do lucro líquido e do retorno sobre o ativo causam menor volume de frases sobre investimentos. Entretanto, variações positivas sobre a liquidez explicam maior volume de frases.

\section{Dividendos}

O volume de frases sobre dividendos é positivamente relacionado a variações no lucro líquido e negativamente relacionado a variações no endividamento.

\section{Perspectivas}

Frases sobre perspectivas são positivamente influenciadas por variações positivas no lucro líquido. Aumentos no endividamento explicam uma menor quantidade de frases.

\section{Proposição 10 - O assunto discutido no RA está relacionado com o desempenho futuro da entidade.}

Foram também calculadas regressões relacionando as variáveis quantitativas de previsão com a quantidade de frases, segundo a classificação apresentada anteriormente neste texto. Não foi possível estabelecer nenhuma relação para as frases relacionadas com investimentos.

\section{Apresentação}

Variações negativas no patrimônio líquido em 2001 causam um menor número de frases sobre apresentação nos relatórios de 2002.

\section{Descrição}

Aumentos no ativo em 2001 explicam um maior número de frases sobre descrição do negócio em 2002; em contrapartida, reduções no patrimônio líquido e no retorno sobre o ativo causam redução deste número. 


\section{Conjuntura}

Variações negativas no ativo e na liquidez causam maior número de frases sobre a conjuntura, enquanto variações positivas do retorno sobre o ativo justificam um menor número de frases.

\section{Reforma}

Variações positivas do patrimônio líquido em 2001 estão associadas a aumentos de frases sobre reforma da administração em 2002.

\section{Desempenho}

Variações positivas sobre o patrimônio e o retorno sobre o ativo em 2001 causam maior quantidade de frases sobre desempenho em 2002.

\section{Auditoria}

Reduções no lucro líquido e no retorno sobre o ativo estão associadas a menores quantidades de frases sobre auditoria em 2002. Variações positivas sobre endividamento explicam um maior número de frases.

\section{Dividendos}

A quantidade futura de frases sobre dividendos está relacionada positivamente a um aumento do lucro líquido em 2001 e negativamente a uma redução no endividamento.

\section{Estrutura de capital}

Variações positivas do patrimônio líquido em 2001 explicam um aumento de frases sobre estrutura de capital em 2002.

\section{Endividamento}

A quantidade de fases sobre endividamento de 2002 está positivamente relacionada a um aumento do retorno sobre o ativo em 2001.

\section{Perspectivas}

Variações negativas no ativo em 2001 causam menor número de frases sobre perspectivas em 2002 enquanto o aumento no retorno sobre o ativo explica maior número de frases. 


\section{Conclusões}

Os Relatórios da Administração possuem grande volume de informações sobre as companhias e são utilizados por acionistas em decisões de investimento. Entretanto alguns teóricos afirmam que estes relatórios são enviesados pelo otimismo da administração.

O objetivo deste estudo foi verificar se os Relatórios da Administração representam fonte de informação sobre a empresa. Para realizá-lo, foram analisados 448 relatórios das companhias abertas do ano de 2002, retirados do site da CVM e observou-se que existem informações relevantes sobre a empresa nestes relatórios e que as variáveis quantitativas de desempenho e qualitativas do relatório de 2001 e 2003 possuem relação com os RA de 2002.

Os principais achados apontam que as empresas de maior porte possuem relatórios mais extensos, ou seja, empresas maiores divulgam mais informações que empresas de menor porte. Verificou-se que o desempenho futuro da empresa influencia a extensão do relatório; e que empresas que apresentam um ativo e patrimônio líquido menor que no passado, apresentaram relatórios pessimistas. Contatou-se que empresas que apresentam crescimento no ativo possuem relatórios mais extensos. Por outro lado, de forma não esperada, observou-se que o aumento no lucro provoca uma redução no relatório. Outra constatação foi a de que os relatórios otimistas apresentam maior volume de frases sobre reforma administrativa; já os relatórios pessimistas centram sua atenção na conjuntura econômica, o que corrobora os achados de Salancik e Meindl (1984) e Staw et al. (1983), citados por Yuthas et al. (2002).

Sugere-se, para pesquisas futuras, a realização de estudos, utilizando-se séries históricas ou analisando se a segregação em setores econômicos influencia a quantidade de informações divulgadas.

\section{Artigo recebido em 17.09.2004. Aprovado em 22.01.2005.}

\section{Referencias Bibliográficas}

Assaf Neto, A. (2002).

Estrutura e análise de balanços. São

Paulo: Atlas.
Boo, E., \&

Simnett, R. (2002).

The information content of management's prospective comments in financially distressed companies: a note. ABACUS, 38(2), 280-295. 
Lei $\mathrm{N}^{\circ} 6.404$, de 15 de dezembro de 1976 (1976, 17 de dezembro).

Dispõe sobre as Sociedades por Ações. Diário Oficial da União. Recuperado em 12 agosto, 2004, de www.planalto.gov.br

Bryan, S. H. (1997).

Incremental information content of required disclosures contained in management discussion and analysis. The Accounting Review, 72(2), 285-301.

Comissão de Valores Mobiliários - CVM. (1987, 28 de dezembro).

Parecer de Orientação CVM $n^{\circ} 15$. Recuperado em 26 novembro, 2003, de http://www.cvm.gov.br

Eng, L. L., \&

Mak, Y. T. (2003, July/August). Corporate governance and voluntary disclosure. Journal of Accounting and Public Policy. 22(4), 325-345.

Freitas, H., \&

Janissek, R. (2000).

Análise léxica e análise de conteúdo: técnicas complementares, seqüenciais e recorrentes para exploração de dados qualitativos. Porto Alegre: Editora Sagra Luzzatto.

Hair, A., \&

Tatham, B. (1998).

Multivariate data analysis. Upper Saddle River: Prentice.

Hendriksen, E. S., \&

Van Breda, Milchel F. (1999).

Teoria da contabilidade. São Paulo: Atlas.

Iudícibus, S. (2000).

Teoria da contabilidade (6th ed.). São Paulo: Atlas.
Lambert, R. A. (2001, December).

Contracting theory and accounting. Journal of Accounting and Economics. 32(1-3), 3-87.

Lima, E. C.P. (1999).

Problema de agência: teoria e aplicações. UnB Contábil, 2(1), 149153.

Niyama, J. K. (1989).

Contribuição à avaliação do nível de qualidade da evidenciação contábil das empresas pertencentes ao Sistema Financeiro Habitacional - SFH. Tese de Doutorado, Faculdade de Economia, Administração e Contabilidade, Universidade de São Paulo, SP, Brasil.

Pava, M. L., \&

Epstein, M. J. (1993).

How good is MD\&A as an investment tool? Journal of Accountancy. 175(3), 51-53.

Ross, S. A.,

Westerfiel, R. W., \&

Jaffe, J. F. (2002).

Administração financeira. Corporate Finance. (A. Z. Sanvicente, Trad.). (2nd ed.). São Paulo: Atlas. (obra original publicada em 1988).

Springer, L. (1992).

Enhancing the annual report: investor relations and the MD\&A. The Journal of Bank Accounting \& Auditing. 5(2), 27-29.

Stadler, I. M., \&

Pérez-Castrillo, J. D. (2001).

An introduction to the economics of information. Oxford: Oxford University. 
Sullivan, M. C., \&

Benke R. L., Jr. (1997).

Comparing introductory financial accounting textbooks. Journal of Accounting Education, 15(2), 181220.

Sunder, S. (2002, December).

Knowing what others know: common knowledge, accounting and capital markets. Accounting Horizons. 16(4), 305-319.

Viegas, W. (1999).

Fundamentos de metodologia científica. Brasília: Editora Universidade de Brasília.

Young, D., \&

Guenther, D. A. (2002).

Financial reporting environments and international capital Mobility. Journal of Accounting Research. 41(3), 553579.

Yuthas, K,

Rogers, R., \&

Dillard, J. F. (2002, November/December). Communicative action and corporate annual reports. Journal of Business Ethics, 41(1-2), 141-157.

Watson, A.,

Shrives, P. \&

Marston, C. (2002, December).

Voluntary disclosure of accounting ratios in the UK. British Accounting Review, 34(4), 289-313.

Weston, J. F., \&

Brigham, E. F. (2000).

Fundamentos da Administração Financeira (S. Stancatti, Trad.). (10th ed.). São Paulo: Makron Books (obra original publicada em 1996). 


\section{APÊNDiCe A: Variáveis do Modelo da Proposição 2}

DATIVO02 = variável dummy referente ao ativo da empresa; caso o ativo de 31/12/2002 seja maior que o ativo de 31/12/2001 a variável dummy assume valor unitário;

DL02 = variável dummy do lucro líquido (L); caso Lde 2002 seja maior que o LLde 2001, DL02 = 1;

DLQUI02 = variável dummy da liquidez corrente (LQUI), sendo igual a unidade se liquidez de 31/12/2002 for superior a de 31/12/2001;

DPLO2 = variável dummy do patrimônio líquido (PL), sendo igual a unidade quando o valor de 31/12/2002 for superior ao de 31/12/2001;

RSA01 = retorno sobre ativo de 2001, medido pela relação entre o lucro líquido de 2001 pelo ativo de 31/12/2001;

RSA02 = retorno sobre ativo de 2002, medido pela relação entre o lucro líquido de 2002 pelo ativo de 31/12/2002;

DRSA02 = variável dummy do RSA de 2002, sendo igual a 1 quando RSA02 $>$ RSA01; $\mathrm{e}$

DENDIV02 = variável dummy da relação entre o passivo circulante e o ativo (ENDIV), ambos de 31/12/2002, sendo igual a 1 quando for maior que o mesmo indicador de 31/12/2001;

$B_{0}, b_{1}, \ldots b_{8}=$ coeficientes da variável dependente; $\mathrm{e}$

$\mathrm{e}=$ erro do modelo.

Apesar das críticas pertinentes ao indicador RSA01 - vide, por exemplo, Assaf Neto (2002) optou-se por utilizá-lo pelo fato de que ele não tem os problemas de sinais presentes no Retorno sobre o Patrimônio Líquido. 


\section{APÉNDICE B: Resultados Estatísticos Obtidos}

\begin{tabular}{|c|c|c|c|c|}
\hline Proposição & Equação & $\mathrm{r}$ & DW & $\mathrm{Fc}$ \\
\hline \multirow[t]{3}{*}{1} & PALAVRA $=-2.318,03+316,699 \operatorname{Ln}($ ATIVO $)$ & 0,38 & 1,593 & 70,393 \\
\hline & $F R A S E=-63,458+8,811 \operatorname{Ln}($ ATIVO $)$ & 0,378 & 1,553 & 69,7646 \\
\hline & LETRA $=-12.767,7+1.741 \operatorname{Ln}($ ATTVO $)$ & 0,392 & 1,574 & 75,904 \\
\hline \multirow[t]{3}{*}{2} & PALAVRA $=1.206,81+1.217,779$ DATIVO02 $-469,922$ DLLO2 & 0,243 & 1,583 & 11,913 \\
\hline & $F R A S E=33,928+35,105$ DATIVO02 $-35,719$ DLLO2 + 23,901 DRSA02 & 0,27 & 1,571 & 9,936 \\
\hline & LETRA $=6.870,804+6.317,805$ DATIVO02 $-2.630,824$ DLLO2 & 0,238 & 1,554 & 11,464 \\
\hline \multirow[t]{3}{*}{3} & PALAVRA $=1.298,305+794,095$ DLL03 & 0,154 & 1,454 & 8,947 \\
\hline & $F R A S E=36,992+22,091 D L L 03$ & 0,154 & 1,433 & 8,835 \\
\hline & LETRA $=6.880,898+4.708,768 D L L 03$ & 0,172 & 1,433 & 11,182 \\
\hline \multirow[t]{2}{*}{4} & 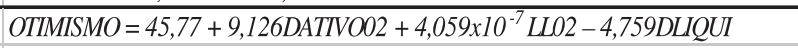 & 0,353 & 2,137 & 10,756 \\
\hline & $+7,259 D P L 02+7,480 \times 10-4 R S A$ & & & \\
\hline 5 & OTIMISMO $=41,517+16,122 D P L 03+7,923 \times 10^{-3}$ RSA03 & 0,396 & 2,009 & 33,987 \\
\hline 6 & PESSIMISMO $=19,783-4,392$ DATIVOO2 $-4,201$ DPLO2 $+3,608 \times 10^{-4}$ RSA01 & 0,263 & 1,983 & 9,435 \\
\hline \multirow[t]{2}{*}{7} & PESSIMISMO $=18,032-4,462$ DATIVO03-3,308DPLO3 $+2,812 \times 10^{-3} R S A 03+$ & 0,226 & 2,041 & 4,87 \\
\hline & 2,788DRSA03 & & & \\
\hline \multicolumn{5}{|l|}{9} \\
\hline apresentação & $Y=13,921-5,873$ DATIVO $-2,73 \times 10^{-7}$ LLO2+4,348DLLO2 & 0,218 & 1,897 & 6,302 \\
\hline descrição & não foi determinado um modelo & & & \\
\hline conjuntura & não foi determinado um modelo & & & \\
\hline reforma & $Y=12,376+8,897$ DATIVO $+3,412 D P L 02-6,460$ DRSA02 & 0,302 & 1,769 & 12,682 \\
\hline desempenho & $Y=19,315+2,041 \times 10^{-7} L L 2+4,089 \times 10^{-4} R S A 01$ & 0,127 & 1,83 & 3,135 \\
\hline auditoria & $Y=5,069-2,50 \times 10^{-8}$ ATIVO02 $-2,19 \times 10^{-7} \mathrm{LOO2}$ & 0,143 & 1,803 & 3,968 \\
\hline investimento & $Y=5,082-2,23 \times 10^{-7} \mathrm{LLO2}+5,298 \times 10^{-4}$ LQUIO2 $-5,31 \times 10^{-4} \mathrm{RSAOI}$ & 0,367 & 1,812 & 19,752 \\
\hline dividendos & $Y=1,465+1,030$ DLLO2-6,61 $\times 10^{-3}$ ENDIVO2 & 0,165 & 1,973 & 5,3 \\
\hline estrut. capital & $Y=4,0361,684 \times 10^{-4}$ ATIVO02 - 1,483 DATIVO02 $+1,269 \times 10^{-7}$ LLO2 & 0,153 & 1,867 & 3,024 \\
\hline endividamento & $Y=2,862-1,001$ DLIQUIO2 & 0,113 & 2,159 & 4,945 \\
\hline perspectiva & $Y=6,241+1,621 D L L 02-1,471 D E N D I V 02$ & 0,14 & 1,972 & 3,783 \\
\hline \multicolumn{5}{|l|}{10} \\
\hline apresentação & $Y=15,104-5,787 D P L 03$ & 0,193 & 1,91 & 14,087 \\
\hline descrição & $Y=12,332+3,177 D A T I V 03-5,154 D P L 03-2,823 R S A 03$ & 0,222 & 1,935 & 6,316 \\
\hline conjuntura & $Y=12,031-3,009 D A T I V 03-1,936 D L U Q U I 03+2,322 R S A 03$ & 0,187 & 2,037 & 4,402 \\
\hline reforma & $Y=11,063+9,455 D P L 03$ & 0,27 & 1,802 & 28,83 \\
\hline desempenho & $Y=15,329+5,078 D P L 03+2,790 R S A 03$ & 0,224 & 1,927 & 9,685 \\
\hline auditoria & $Y=5,799-2,281 D L L 03-2,342 R S A 03+1,937 D E N D I V 03$ & 0,237 & 1,973 & 7,22 \\
\hline investimento & não foi determinado um modelo & & & \\
\hline dividendos & $Y=3,354+2,06 D L L 03-3,433 D R S A 03-1,469 D E N D I V 03$ & 0,263 & 1,938 & 9,025 \\
\hline estrut. capital & $Y=2,299+1,349 D P L 03$ & 0,105 & 1,925 & 4,052 \\
\hline endividamento & $Y=1,779+1,109 D R S A 03$ & 0,12 & 2,098 & 5,376 \\
\hline perspectiva & $Y=7,041-1,752$ DATIV03+1,672RSA03 & 0,156 & 2,018 & 4,569 \\
\hline
\end{tabular}

